\title{
Erratum to: The effect of resveratrol on angiotensin II levels and the rate of transcription of its receptors in the rat cardiac hypertrophy model
}

Fahimeh Dorri Mashhadi ${ }^{1} \cdot$ Javad Zavvar Reza $^{2} \cdot$ Mohabbat Jamhiri $^{1}$ •

Zeinab Hafizi ${ }^{1} \cdot$ Fatemeh Zare Mehrjardi $^{1} \cdot$ Fatemeh Safari $^{1}$

Published online: 21 December 2016

(C) The Physiological Society of Japan and Springer Japan 2016

\section{Erratum to: J Physiol Sci}

DOI 10.1007/s12576-016-0465-0

The first part of Fig. 3 was published incorrectly in the original publication of the article. The corrected figure is given with this erratum.

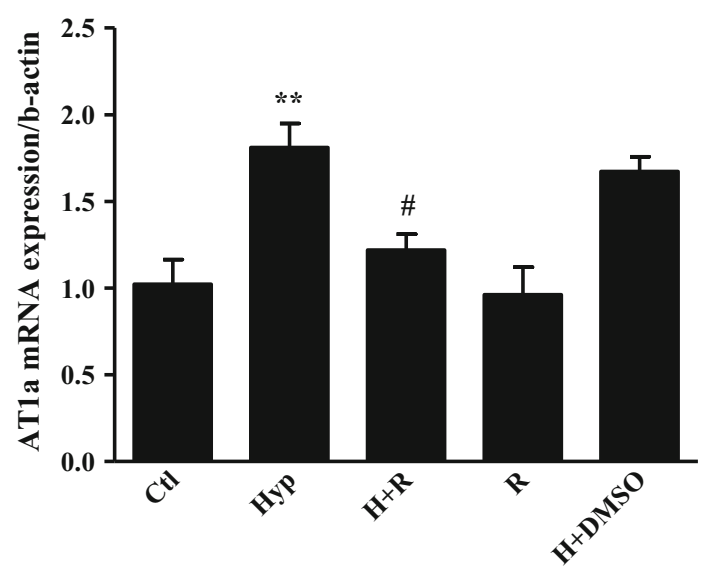

The online version of the original article can be found under doi: 10.1007/s12576-016-0465-0.

Fatemeh Safari

sa.physiol@gmail.com

1 Department of Medical Physiology, Faculty of Medicine, Shahid Sadoughi University of Medical Sciences, Yazd, Iran

2 Department of Clinical Biochemistry, Faculty of Medicine, Shahid Sadoughi University of Medical Sciences, Yazd, Iran 